\title{
Impact of observational training on endoscopic mucosal resection outcomes and competency for large colorectal polyps: single endoscopist experience
}

\section{두)(요우}

Authors

Jeffrey K. Lee ${ }^{*}, 1,2,5$, Trilokesh D. Kidambi ${ }^{*}{ }^{3}$, Tonya Kaltenbach ${ }^{4,5}$, Yasser M. Bhat ${ }^{6}$, Amandeep Shergill4,5, Kenneth R. McQuaid $^{4,5}$, Jonathan P. Terdiman ${ }^{5}$, Roy M. Soetikno ${ }^{4,7}$

Institutions

1 Department of Gastroenterology, Kaiser Permanente San Francisco Medical Center, San Francisco, California, United States

2 Kaiser Permanente Division of Research, Oakland, California, United States

3 Division of Gastroenterology, City of Hope National Medical Center, Duarte, California, United States

4 San Francisco Veterans Affairs Healthcare System, San Francisco, California, United States

5 Division of Gastroenterology, University of California, San Francisco, San Francisco, California, United States

6 Division of Gastroenterology, Palo Alto Medical Foundation, Palo Alto, California, United States

7 Advanced Gastrointestinal Endoscopy, Mountain View, California, United States

submitted 25.6.2019

accepted after revision $\quad 2.12 .2019$

Bibliography

DOI https://doi.org/10.1055/a-1107-2711 |

Endoscopy International Open 2020; 08: E346-E353

(c) Georg Thieme Verlag KG Stuttgart · New York eISSN 2196-9736

Corresponding author Jeffrey K. Lee MD, MAS, Kaiser Permanente Division of Research, 2000 Broadway, Oakland, California

Fax: +1-626-256-8643

jeffrey.k.lee@kp.org

丹 Supplementary material

Online content viewable at:

https://doi.org/10.1055/a-1107-2711

\section{ABSTRACT}

Background and study aims Endoscopic mucosal resection (EMR) is standard treatment for large colorectal polyps. However, it is a specialized technique with limited data on the effectiveness of training methods to acquire this skill. The aim of this study was to evaluate the impact of observational training on EMR outcomes and competency in an early-stage endoscopist.

Patients and methods A single endoscopist completed comprehensive EMR training, which included knowledge acquisition and direct observation of EMR cases, and proctored supervision, during the third year of gastroenterology fellowship. After training, EMR was independently attempted on 142 consecutive, large (i. e., $\geq 20 \mathrm{~mm}$ ), non-pedunculated colorectal polyps between July 2014 and December 2017 (mean age 61.7 years; mean polyp size 30.4 mm; enbloc resection $55 \%$ ). Surveillance colonoscopy for evaluation of residual neoplasia was available for $86 \%$ of the cases. Three primary outcomes were evaluated: endoscopic assessment of complete resection, rate of adverse events (AEs), and rate of residual neoplasia on surveillance colonoscopy.

Results Complete endoscopic resection was achieved in $93 \%$ of cases, the rates of AEs and residual neoplasia were $7.8 \%$ and $7.3 \%$, respectively. The rate of complete resection remained stable (at $85 \%$ or greater) with increasing experience while rates of AEs and residual neoplasia peaked and decreased after 60 cases.

Conclusions An early-stage endoscopist can acquire the skills to perform effective EMR after completing observational training. At least 60 independent EMRs for large colorectal polyps were required to achieve a plateau for clinically meaningful outcomes.

\footnotetext{
* Drs. Lee and Kidambi: These authors contributed equally.
} 


\section{Introduction}

Endoscopic mucosal resection (EMR) has been shown to be safe and effective for large colorectal polyps, with the additional benefits of avoidance of surgery and cost-savings [1-11]. As a result, it is considered standard of care over the invasive alternative of surgical resection for benign lesions, which is supported by the recommendations of the European Society of Gastrointestinal Endoscopy (ESGE) [2]. However, a recent study [12] showed an alarming increase in rates of surgery for benign colorectal polyps in the United States between 2000 and 2014. While the cause of this is not known, one hypothesized explanation relates to perceived risk of endoscopic removal of large polyps by endoscopists without adequate training in advanced resection techniques.

EMR for large colorectal polyps is a specialized endoscopic skill that can be technically challenging [11]. As described in a review of colorectal EMR [13], it is a "quantum leap above standard colon polypectomy" and, as such, requires dedicated training and competency assessment. Currently, EMR training and competency assessment may be obtained as one component of an advanced endoscopy fellowship in the United States; however, this approach is impractical for established gastroenterologists who are unable to dedicate a year to acquire this skill set. Although informal training for colorectal EMR such as weekend didactic and hands-on courses, educational videos, and industry-sponsored on-site preceptorships exist, there is no data on the effectiveness of these programs in ensuring EMR competency and no published data on EMR outcomes from clinicians who have trained in these types of programs. There are, at best, limited suggestions and guidance on a core EMR curriculum [14]. Furthermore, only a single prior study [15] examined the learning curve of colon EMR among three established, academic advanced endoscopists. Few studies to date have reported EMR outcomes in the West and nearly all data on rate of en-bloc resection, residual neoplasia, and adverse events (AEs) have come from experienced endoscopists.

Dedicated observational training in the time-honored, mentor-apprenticeship setting is an established model for endoscopic training in the East with published data of successful adoption amongst Western endoscopists, particularly in the setting of endoscopic submucosal dissection (ESD) [16]. However, there are no data on colon EMR outcomes among earlystage endoscopists.

Thus, the aim of our study was to evaluate the impact of dedicated observational training on EMR outcomes and competency in an early-stage endoscopist without advanced endoscopy training.

\section{Patients and methods}

\section{Study population and setting}

A retrospective review was performed of an endoscopy database of patients with colorectal polyps $20 \mathrm{~mm}$ or larger managed by a single endoscopist (JKL) that was created in July 2014. All procedures were performed at the University of California, San Francisco (UCSF), an academic, tertiary care medical center serving over 1.2 million patients annually in the San Francisco Bay Area. The institutional review board at UCSF granted permission to review the database and the patients' corresponding electronic health records. Inclusion criteria were all consecutive adult patients 18 years of age or older who underwent a colonoscopy and EMR for a non-pedunculated (i.e., sessile or flat) polyp $20 \mathrm{~mm}$ or larger between July 2014 and December 2017. Polyps that appeared to have endoscopic features of invasive cancer (e.g., amorphous vessel pattern, fold convergence, etc.) were excluded from the analyses.

\section{EMR experience and training}

The studied endoscopist (JKL) completed a 3-year general gastroenterology fellowship at an academic institution, which included 6 months of training in advanced imaging and resection techniques at a separate institution (Palo Alto Veteran Affairs Medical Center) during the end of his general gastroenterology fellowship training. Advanced imaging and resection training consisted of knowledge acquisition through readings and videos, and direct observation of multiple EMR cases (once weekly on-site with observation of 64 cases over the six-month span) performed by two attending advanced endoscopists (RMS and TK). Advanced imaging and endoscopic resection topics that were taught through readings are summarized in Supplemental Table 1, which included lesion characterization, principles of electrocautery, injection fluid and technique (e.g., dynamic injection) [17], resection technique, and prevention and management of adverse events (e.g., perforation, bleeding). In addition to readings, the trainee had to review videos of EMR and ESD procedures. Knowledge competency for each topic was determined during each observational session by the mentor (RMS) using the Socratic method (the use of questions and active learning to stimulate critical thinking, analysis of problems with the ultimate goal of developing a deeper understanding of the topic). Towards the end of the training program, the endoscopist performed 10 EMRs on colorectal polyps, ranging from $15 \mathrm{~mm}$ to $20 \mathrm{~mm}$ in size, at the local training institution (San Francisco Veteran Affairs Medical Center) under the direct supervision (with only verbal assistance) of an attending advanced endosocopist (YMB). No animal models were used for EMR training during the period. Upon completing gastroenterology fellowship, the endoscopist practiced independently from July 2014 and kept a log of all EMR cases along with photos for review and feedback from the two endoscopic resection experts (RMS and TK). Review and feedback of cases were done electronically and remotely through submission of photos and outcomes.

\section{EMR procedure}

After standard bowel preparation using a split-dose polyethylene glycol-electrolyte solution, colonoscopy was performed using a high-definition colonoscope (Pentax EC-3890 or EC3490) equipped with electronic chromoendoscopy capability (i-scan) for detection and characterization of all lesions. Macroscopic appearance of all lesions was described using the Paris classification. The diameter of each lesion was estimated using an open polypectomy snare before endoscopic therapy. After 
lesion morphology characterization, the polyps were dynamically injected [17] using saline mixed with a small amount of methylene blue into the submucosal plane until sufficient lifting of the lesion was achieved. A 20-mm-diameter stiff snare (Olympus, Snaremaster) was used for en-bloc resection of the lesion (setting: EndoCut Q 3-1-3; Erbe: Marietta, Georgia, United States). If en-bloc resection was not technically possible, resection was carried out using a piecemeal technique with the $20 \mathrm{~mm}$ stiff snare or smaller snares (e.g., $11 \mathrm{~mm}, 13 \mathrm{~mm}$, or $15 \mathrm{~mm}$, Boston Scientific). In instances where small islands or bridges $(<5 \mathrm{~mm})$ of definite residual polyp were seen endoscopically despite multiple snare resection, hot forcep avulsion (setting: EndoCut Q 3-1-3; Erbe: Marietta, Georgia, United States) and/or argon plasma coagulation (APC) was applied in short bursts to treat the residual areas (20 W to $40 \mathrm{~W}$, Erbe APC 300 or APC VIO, with the Erbe APC 2200 straight-fire flexible probe; Erbe Elektromedizin, Tübingen, Germany). Any immediate bleeding during the colorectal EMR procedure was treated with soft-tip coagulation (using the tip of the snare) and/or hemostatic grasper (Olympus, coagrasper hemostatic forceps). Lastly, endoscopic hemoclip(s) (Cook Medical, hemoclips) were utilized to seal the EMR defect. Resected polyps were sent for pathologic examination as part of routine clinical care and histology of polyps was evaluated by expert gastrointestinal pathologists at UCSF. A submucosal injection of Spot (GI supply Inc, Camp Hill, Pennsylvania, United States) tattoo was placed distal to the lesion to allow for localization on subsequent surveillance exams. The approach to EMR is summarized in Supplemental Table 2.

\section{Post-EMR follow-up}

All patients were called 24 hours and 14 days and 30 days after EMR to assess for AEs. The first follow-up colonoscopy was recommended at 6 months after EMR. All surveillance colonoscopies were performed by the same endoscopist (JKL). The EMR scar was identified endoscopically and by the presence of tattoo. During follow-up colonoscopy, any macroscopically visible neoplastic tissue was removed by either cold biopsy forceps or snare devices for histological evaluation. All EMR scars were closely inspected with high-definition imaging along with electronic chromoendoscopy. If no visible polypoid tissue was seen, the center and lateral portions of the EMR scar were biopsied using cold forceps.

\section{Data collection and outcomes}

Data from all patients were extracted from the electronic health records using manual chart review by a single investigator (TDK) including baseline demographic characteristics, American Society of Anesthesiologists (ASA) class, aspirin use, antithrombotic (e.g., clopidogrel, warfarin, direct oral anticoagulants) use, referral information (versus polyp identification as part of routine screening or surveillance colonoscopy), and prior endoscopic manipulation (e.g., prior forcep biopsy or prior attempt at polyp resection with snare and cautery). Procedural data such as polyp location, polyp size, Paris classification, polyp histology, en-bloc versus piecemeal EMR, EMR technique specifics, and use of prophylactic clips were also collec- ted. Data from subsequent surveillance colonoscopies, when performed, were gathered.

Three primary outcomes were measured: 1 ) endoscopist assessment of complete resection defined as no residual polypoid tissue on careful observation of the EMR defect using white light and electronic chromoendoscopy; 2) AEs including perforation, post-EMR severe bleeding, and post-polypectomy syndrome; and 3) residual neoplasia at follow-up defined as the presence of macroscopically visible neoplastic tissue at the polypectomy scar or the presence of residual neoplasia on surveillance biopsies confirmed histologically. Post-EMR severe bleeding was defined as an event occurring within 30 days after EMR that required hospitalization, need for repeat endoscopy, need for a blood transfusion, or need for any other major intervention. Post-EMR severe bleeding was stratified as early (occurring within 24 hours after EMR) and delayed (occurring $>24$ hours after EMR).

\section{Statistical analysis}

Descriptive statistics were used to characterize all patients and lesions. Continuous variables were summarized using the mean, median, standard deviation, and range; categorical variables were presented using the number and percentage. The three primary outcomes were assessed using a combination of descriptive summaries and graphical evaluation [15]. Specifically, EMR cases were divided chronologically into groups of 20 sequential EMRs, determined a priori based on a prior study [15], and rates of the primary outcomes were calculated; these data were also represented graphically. In addition, established risk factors associated with neoplasia recurrence after EMR [18] such as polyp size, prior manipulation (prior biopsy, snare and/ or injection), and en-bloc resection were analyzed according to sequential EMR cases. Analyses were performed using STATA 13.0 (StataCorp, College Station, Texas, United States).

\section{Results}

\section{Patient characteristics}

Between July 1, 2014 and December 15, 2017, 145 patients were identified in the database with a large, non-pedunculated colorectal polyp ( $\mathbf{F i g . 1}$ ). In three cases, EMR was not attempted due to concern for frank malignancy based on the endoscopic appearance - all of these patients underwent surgical resection with histology confirming adenocarcinoma. EMR was attempted on the remaining 142 patients. - Table 1 shows the full demographic information for the 142 patients who underwent EMR.

Mean patient age was 61.7 years (range $26-87$ ), with a similar distribution of men and women (men, 50.7\%). While most patients were white (69.0\%), Hispanics and Asians accounted for greater than one-quarter of the patients (27.5\%). Aspirin use was common $(27.5 \%)$ and most procedures were performed with moderate sedation (70.4\%). 
All patients with a non-pedunculated,

large $(\geq 20 \mathrm{~mm})$ colorectal polyp $(n=145)$

EMR not attempted

- suspicion of submucosally invasive cancer, $\mathrm{n}=3$

Patients who underwent an attempted EMR $(n=142)$

Failed EMR and required surgery

- technical difficulty, $\mathrm{n}=4$

\section{Patients who had successful EMR $(n=138)$}

Did not complete first surveillance colonoscopy,

$\mathrm{n}=15$

- death due to unrelated cardiac event: $n=1$

- colon cancer requiring surgical resection; $n=1$

- not covered by medical insurance: $n=6$

- concern about significant medical comorbidity: $n=3$

- unable to contact for follow-up: $n=4$

Completed first surveillance colonoscopy to assess for residual neoplasia $(n=123)$

- Fig. 1 Flow diagram for cohort selection.

\section{EMR characteristics and outcomes}

Among the 142 EMR cases, four were unsuccessful and these patients underwent surgical resection-in all cases, technical failure was due to extensive scarring from previously attempted endoscopic intervention by the referring physician. The remaining 138 patients had a successful EMR. The majority of the lesions were located in the ascending colon (61.3\%) and had a flat morphology (57\%, Paris 2a, > Table 2). Mean lesion size was $30.4 \mathrm{~mm}$ (median $25 \mathrm{~mm}$, range $20 \mathrm{~mm}$ to $100 \mathrm{~mm}$ ). Among the 142 EMR cases, 78 cases (54.9\%) were referred for EMR, and of those referred, 64 cases had been biopsied and 10 cases had previous attempt at resection with snare and cautery.

Most lesions were conventional adenomas while sessile serrated adenomas accounted for $38 \%$ of cases; high-grade dysplasia was found in $9.2 \%$ of cases. Of the two EMR cases in which histology showed adenocarcinoma, one patient died (cardiac event) before her scheduled surveillance and the other patient underwent successful surgical resection.

Of the 138 patients who had a successful EMR, 123 underwent surveillance colonoscopy (median time to surveillance 182 days, range 48 days to 715 days). A macroscopically visible EMR scar was identified in all surveillance colonoscopies.

EMR primary outcomes are shown in $>$ Table 3 . There was one case of perforation $(0.7 \%)$, which did not require surgery and was managed successfully endoscopically with clip closure. All cases of early bleeding (1.4\%) were managed successfully
- Table 1 Baseline patient information.

\begin{tabular}{|c|c|}
\hline & All patients $(n=142)$ \\
\hline Mean age (years) & 61.7 (range $26-87 ;$ SD 10.3) \\
\hline Male & $72(50.7)$ \\
\hline \multicolumn{2}{|l|}{ Race/ethnicity } \\
\hline - White & $98(69.0)$ \\
\hline - Hispanic & $19(13.4)$ \\
\hline - Black & $5(3.5)$ \\
\hline - Asian & $20(14.1)$ \\
\hline \multicolumn{2}{|l|}{ ASA class } \\
\hline - 1 & $38(26.8)$ \\
\hline .2 & $71(50.0)$ \\
\hline - 3 & $31(21.8)$ \\
\hline - 4 & $2(1.4)$ \\
\hline Moderate sedation & $100(70.4)$ \\
\hline $\begin{array}{l}\text { Anesthesiologist administered } \\
\text { sedation }\end{array}$ & $42(29.6)$ \\
\hline Mean body mass index & 27.6 (SD 5.6) \\
\hline Aspirin use & $39(27.5)$ \\
\hline Antithrombotic use ${ }^{1}$ & $11(7.8)$ \\
\hline \multicolumn{2}{|c|}{$\begin{array}{l}\text { ASA, American Society of Anesthesia classification; EMR, endoscopic muco- } \\
\text { sal resection; SD, standard deviation } \\
\text { Unless otherwise specified, values listed as number [n, (\%)]. } \\
{ }^{1} \text { Clopidogrel, warfarin, direct oral anticoagulants }\end{array}$} \\
\hline
\end{tabular}

endoscopically without the need for transfusion. Of the six cases of delayed bleeding (4.2\%), only one patient required blood transfusion and this case was also successfully managed endoscopically; the remaining were observed without need for intervention. Neither case of post-polypectomy syndrome (1.4\%) required inpatient hospital admission.

Of the nine cases $(7.3 \%)$ in which residual neoplasia were found on surveillance colonoscopy, all were of polyps that were removed initially in a piecemeal fashion and eight were of polyps in which prior resection and/or extensive biopsies were performed (two with prior attempted snare resection and six with extensive biopsies of the lesion). Additional details regarding these cases are shown in Supplemental Table 3. Residual neoplasia was endoscopically evident in all cases during surveillance colonoscopy with high-definition imaging along with electronic chromoendoscopy. All residual neoplasia on follow-up were small (i. e., $<10 \mathrm{~mm}$ ) and managed endoscopically, without surgery. Surveillance colonoscopy after endoscopic resection of residual neoplasia was performed in all nine cases with no evidence of recurrence. 
- Table 2 EMR information.

\begin{tabular}{|c|c|}
\hline & All patients $(n=142)$ \\
\hline \multicolumn{2}{|l|}{ Polyp location } \\
\hline Cecum & $13(9.2)$ \\
\hline Ascending colon & $87(61.3)$ \\
\hline Hepatic flexure & $7(4.9)$ \\
\hline Transverse colon & $7(4.9)$ \\
\hline Splenic flexure & $1(0.7)$ \\
\hline Descending colon & $4(2.8)$ \\
\hline Sigmoid colon & $11(7.8)$ \\
\hline Rectum & $4(2.8)$ \\
\hline Ileocecal valve & $6(4.2)$ \\
\hline Appendiceal orifice & $2(1.4)$ \\
\hline Mean polyp size (mm) & 30.4 (SD 15.5) \\
\hline Median polyp size (mm) & 25.0 (range $20-100$ ) \\
\hline \multicolumn{2}{|l|}{ Paris classification } \\
\hline . Is & $39(27.5)$ \\
\hline - Is+lla & $18(12.7)$ \\
\hline - Ila & $82(57.8)$ \\
\hline - IIb & $1(0.7)$ \\
\hline - IIc & $1(0.7)$ \\
\hline - IIa+IIc & $1(0.7)$ \\
\hline Referral for EMR & $78(54.9)$ \\
\hline Prior biopsy of lesion & $64(45.1)$ \\
\hline Prior snare of lesion & $10(7.0)$ \\
\hline En bloc resection & $78(54.9)$ \\
\hline Prophylactic clip placement & $125(88.0)$ \\
\hline \multicolumn{2}{|l|}{ Pathology } \\
\hline - High-grade dysplasia & $13(9.2)$ \\
\hline - Villous adenoma & $1(0.7)$ \\
\hline - Tubulovillous adenoma & $18(12.7)$ \\
\hline - Tubular adenoma & $52(36.6)$ \\
\hline - Sessile serrated adenoma & $54(38.0)$ \\
\hline - Traditional serrated adenoma & $2(1.4)$ \\
\hline - Adenocarcinoma & $2(1.4)$ \\
\hline
\end{tabular}

\section{EMR outcomes by increasing experience}

The rate of the primary outcomes of complete resection, AEs and residual neoplasia as a function of EMR experience is displayed graphically in $>$ Fig. 2 . As shown, there was a decrease
- Table 3 EMR outcomes.

\begin{tabular}{|l|c|}
\hline & Summary \\
\hline Endoscopic assessment of complete resection & $132 / 142(93.0 \%)$ \\
\hline Adverse event & $11 / 142(7.8 \%)$ \\
\hline Perforation & $1 / 142(0.7 \%)$ \\
\hline Early bleed & $2 / 142(1.4 \%)$ \\
\hline Delayed bleed & $6 / 142(4.2 \%)$ \\
\hline Post-polypectomy syndrome & $2 / 142(1.4 \%)$ \\
\hline Residual neoplasia on follow-up & $9 / 123(7.3 \%)$ \\
\hline EMR, endoscopic mucosal resection & \\
\hline
\end{tabular}

in the rate of complete resection between EMRs 21 to 40 (to $85 \%$ from $100 \%$ ) with a concurrent increase in the rate of AEs (from $0 \%$ to $15 \%$ ) and residual neoplasia (from $5.6 \%$ to $27.8 \%$ ). After 60 cases, the rate of complete resection reached and maintained its peak (at least $85 \%$ ) while rates of residual neoplasia and adverse events plateaued to $10 \%$ or less. There were increases in factors associated with polyp recurrence such as polyp size and prior endoscopic manipulation in cases 21 to 40 as compared to 1 to 20, but these factors remained stable for subsequent cases (cases 41-142).

\section{Discussion}

We showed the potential to learn colon EMR through the timehonored, mentor-apprenticeship learning method consisting of knowledge acquisition of advanced imaging and resection techniques and direct observation of EMR cases by an earlystage endoscopist, followed by proctored supervision of cases and feedback on independently performed EMRs. In our study of 142 non-pedunculated polyps $\geq 20 \mathrm{~mm}$, complete endoscopic resection was achieved in $93 \%$ of cases after this training and rates of adverse events and residual neoplasia were $7.8 \%$ and $7.3 \%$, respectively. We found after 60 independent colon EMRs, rates of complete resection reached a peak and rates of AEs and residual neoplasia reached a plateau, which remained stable over the remainder of the study period.

Outcomes in this study can be compared to the single published study [15] of EMR learning curves for large colorectal polyps, which reported outcomes of three academic advanced endoscopists without appreciable EMR experience prior to the examined period. The study identified a threshold of 100 EMRs for large colorectal polyps to achieve rates of residual neoplasia below $20 \%$ and complete resection above $75 \%$. Possible explanations for differences between the prior study and the current one include the number of endoscopists (three), varying EMR technique, type of EMR training (not specified in the previous study), and prior therapy ( $15 \%$ had prior endoscopic therapy in the previous study, which is higher than the present study). Irrespective of these differences, it is clear that further data from endoscopists across different practice settings are necessary to understand the learning curve of colorectal EMR. 


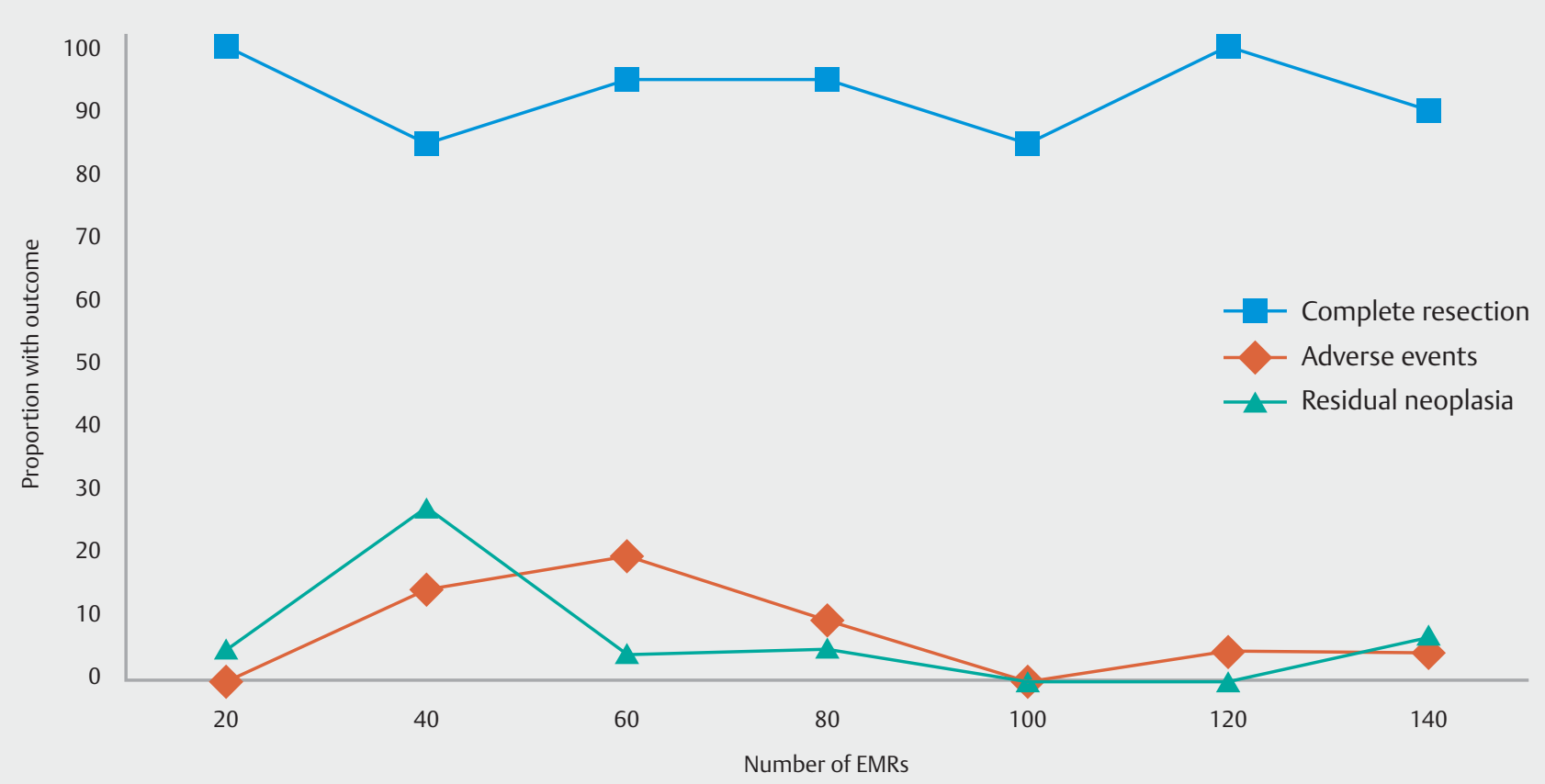

\begin{tabular}{|l|l|l|l|l|l|l|l|}
\hline $\begin{array}{l}\text { EMR } \\
\text { number }\end{array}$ & $\begin{array}{l}\text { Complete } \\
\text { resection }\end{array}$ & $\begin{array}{l}\text { Adverse } \\
\text { events }\end{array}$ & $\begin{array}{l}\text { Residual } \\
\text { neoplasia }\end{array}$ & $\begin{array}{l}\text { Median size } \\
(\mathbf{m m})\end{array}$ & $\begin{array}{l}\text { Mean size } \\
(\mathbf{m m})\end{array}$ & $\begin{array}{l}\text { Prior manipu- } \\
\text { lation* }\end{array}$ & $\begin{array}{l}\text { En bloc } \\
\text { resection }\end{array}$ \\
\hline $1-20$ & $20 / 20(100 \%)$ & $0 / 20(0 \%)$ & $1 / 18(5.6 \%)$ & 20 & 21.4 & $2 / 20(10 \%)$ & $15 / 20(75 \%)$ \\
\hline $21-40$ & $17 / 20(85 \%)$ & $3 / 20(15 \%)$ & $5 / 18(27.8 \%)$ & 25 & 32.5 & $10 / 20(50 \%)$ & $10 / 20(50 \%)$ \\
\hline $41-60$ & $19 / 20(95 \%)$ & $4 / 20(20 \%)$ & $1 / 20(5 \%)$ & 25 & 28.3 & $8 / 20(40 \%)$ & $12 / 20(60 \%)$ \\
\hline $61-80$ & $19 / 20(95 \%)$ & $2 / 20(10 \%)$ & $1 / 18(5.6 \%)$ & 20 & 35.0 & $13 / 20(65 \%)$ & $9 / 20(45 \%)$ \\
\hline $81-100$ & $17 / 20(85 \%)$ & $0 / 20(0 \%)$ & $0 / 18(0 \%)$ & 25 & 30.3 & $8 / 20(40 \%)$ & $10 / 20(50 \%)$ \\
\hline $101-120$ & $20 / 20(100 \%)$ & $1 / 20(5 \%)$ & $0 / 17(0 \%)$ & 28 & 29.3 & $11 / 20(55 \%)$ & $11 / 20(55 \%)$ \\
\hline $121-140$ & $18 / 20(90 \%)$ & $1 / 20(5 \%)$ & $1 / 13(7.7 \%)$ & 30 & 36.3 & $10 / 20(50 \%)$ & $11 / 20(55 \%)$ \\
\hline $141-142$ & $2 / 2(100 \%)$ & $0 / 2(0 \%)$ & $0 / 1(0 \%)$ & 33 & 32.5 & $2 / 2(100 \%)$ & $0 / 2(0 \%)$ \\
\hline
\end{tabular}

- Fig. 2 EMR outcomes by increasing experience.

* prior manipulation includes prior biopsy, snare attempt, and/or injection.

EMR outcomes in our study were consistent with those described in the Western literature (Supplemental Table 4) [8, $9,15,19-23]$. These results suggest that gastroenterologists without additional formal advanced endoscopy training can acquire the necessary skill set for EMR through dedicated, comprehensive training. This rigorous training consisted of knowledge acquisition through readings and videos, direct observation of multiple EMR cases (i. e., 64 cases) performed by gastroenterologists skilled in advanced endoscopic resection techniques, and performance of EMRs by the trainee under direct supervision. In addition, remote electronic feedback was continued upon independent practice allowing for learning beyond the initial training period. The time-honored, mentor-apprenticeship model of learning endoscopic techniques through direct observational and educational training from experts has been successfully utilized for ESD in the East [24] and in the
West [16]. While the specific skill set for ESD differs from EMR, the finding that specific training can lead to competency and acceptable outcomes in inexperienced endoscopists is consistent. With the rise of new forms of EMR training in the postgraduate setting through courses such as the ESGE Days hands-on training sessions, the American Society for Gastrointestinal Endoscopy Skills Training Assessment Reinforcement (STAR) certificate program, video-based learning, industrysponsored preceptorships, and use of animal models [13], there are now a variety of learning opportunities available. However, further studies are needed to determine whether any of these other models are effective and translate to acceptable clinical outcomes.

Currently, there is a paucity of data for learning curves, competency assessments, and procedural volume thresholds for colorectal EMR as compared with other advanced procedures. 
Learning curves for endoscopic ultrasound and ERCP, for example, have been studied in a prospective, multicenter study [25] and the analyses suggests that competence-based assessments (for which validated tools exist) rather than an emphasis on pure procedural volume thresholds are more indicative of technical success and mastery. Even with ESD for colorectal neoplasia, which has far fewer indications than EMR [26, 27], there are data supporting a procedural threshold of 40 cases to minimize perforations and 80 cases to maximize en-bloc resections among endoscopists with gastric ESD experience [28]. Thus, it is surprising that there is little data on EMR for large colorectal polyps, given its broader applicability to gastroenterology practice. Furthermore, it is imperative that endoscopists are able to effectively perform colon EMR in the United States, given the large number of surgical resections for benign colorectal polyps $[12,26]$. Ultimately, as further data on learning curves in colon EMR become available, a more sophisticated understanding of the teaching and learning process (beyond procedural volume thresholds) may lead to effective assessments of competency.

Our results should be interpreted in the context of the study's limitations. Only a single early career endoscopist was included, and as such, the results may not be generalizable. However, most studies on EMR for large colorectal polyps only report outcomes from a single endoscopist (Supplemental Table 4). Sequential cases were examined in an attempt to assess the impact of experience on the outcomes, though it is possible that unmeasured factors were associated with the outcomes such as subtle changes in endoscopic techniques. Our perspective was that these potential changes likely reflected the learning process associated with practice and experience. As all cases were carried out at an academic tertiary care center, there may be limits on generalizability; however, half the cases were not referred and found on screening or surveillance colonoscopy which strengthens the generalizability of the results in a non-referral practice. The number of pieces resected in the piecemeal EMRs was also not recorded, which may have contributed to rates of residual neoplasia. Additionally, it should be recognized that the training method in this study was an intensive and extended observational training with didactics, and feedback of cases post-observation and our findings do not obviate other training methods such as proctored hands-on experience on simulators or real patients or a combination of both. More research is needed to better understand the effectiveness of other training methods for EMR given that the practicality for gastroenterologists to observe and train from expert endoscopists for an extended period of time is likely to be limited. Lastly, we cannot exclude selection bias from incomplete follow-up data for surveillance, though having $86 \%$ follow-up is well within the range expected based on previous studies. In any case, it is possible that the rate of residual neoplasia could be higher than identified.

\section{Conclusion}

In summary, we found that an EMR skill set can be successfully acquired through comprehensive training consisting of knowledge acquisition of advanced imaging and resection tech- niques, direct observation of EMR cases, proctored supervision of cases, and feedback while in independent practice. This training can result in EMR outcomes similar to that reported in the Western literature. Our data suggest that by 60 colon EMR cases, the rate of residual neoplasia decreases and achieves an acceptable plateau with no effect of increasing experience on rates of complete resection and adverse events. With various EMR training opportunities available, we await more studies evaluating the effectiveness of these training methods, ultimately with the goal of developing and validating tools to improve and optimize EMR outcomes.

\section{Acknowledgement}

This work was supported by grants from the National Cancer Institute (K07CA212057) and American Gastroenterological Association, both to Dr. Lee.

\section{Competing interests}

Dr. Lee received research funding from Pentax Medical. Pentax had no role in study design, data collection, decision to submit the manuscript for publication, and drafting of the manuscript. Dr Kaltenbach is a consultant for Olympus. Olympus had no role in study design, data collection, decision to submit the manuscript for publication, and drafting of the manuscript. Dr. Shergill received a research gift from Pentax Medical. Pentax had no role in study design, data collection, decision to submit the manuscript for publication, and drafting of the manuscript. Dr Soetikno is a consultant for Olympus. Olympus had no role in study design, data collection, decision to submit the manuscript for publication, and drafting of the manuscript.

References

[1] Conio M, Ponchon T, Blanchi S et al. Endoscopic mucosal resection. Am J Gastroenterol 2006; 101: 653-663

[2] Ferlitsch M, Moss A, Hassan C et al. Colorectal polypectomy and endoscopic mucosal resection (EMR): European Society of Gastrointestinal Endoscopy (ESGE) clinical guideline. Endoscopy 2017; 3: 270297

[3] Tanaka S, Oka S, Chayama K et al. Knack and practical technique of colonoscopic treatment focused on endoscopic mucosal resection using snare. Dig Endosc 2009; 21: S38-S42

[4] Hwang JH, Konda V. ASGE Technology Committee. et al. Endoscopic mucosal resection. Gastrointest Endosc 2015; 82: 215-226

[5] Rao AK, Soetikno R, Raju GS et al. Large sessile serrated polyps can be safely and effectively removed by endoscopic mucosal resection. Clin Gastroenterol Hepatol 2016; 14: 568-574

[6] Ma MX, Bourke M]. Complications of endoscopic polypectomy, endoscopic mucosal resection and endoscopic submucosal dissection in the colon. Best Pract Clin Gastroenterol 2016; 30: 749-767

[7] Jayanna M, Burgess NG, Singh R et al. Cost analysis of endoscopic mucosal resection vs surgery for large laterally spreading colorectal lesions. Clin Gastroenterol Hepatol 2016; 14: 271-278 e271-272

[8] Raju GS, Lum PJ, Ross WA et al. Outcome of emr as an alternative to surgery in patients with complex colon polyps. Gastrointest Endosc 2016; 84: 315-325

[9] Moss A, Williams S], Hourigan LF et al. Long-term adenoma recurrence following wide-field endoscopic mucosal resection (WF-EMR) for advanced colonic mucosal neoplasia is infrequent: Results and risk 
factors in 1000 cases from the australian colonic EMR (ACE) study Gut 2015; 64: 57-65

[10] Hassan C, Repici A, Sharma P et al. Efficacy and safety of endoscopic resection of large colorectal polyps: A systematic review and meta-analysis. Gut 2016; 65: 806-820

[11] Conio M. Competency in endoscopic mucosal resection. Gastrointest Endosc 2016; 84: 969-970

[12] Peery AF, Cools KS, Strassle PD et al. Increasing rates of surgery for patients with nonmalignant colorectal polyps in the United States. Gastroenterology 2018; 5: 1352-1360

[13] Lee RF, Heitman SJ, Bourke MJ. Training and competency in endoscopic mucosal resection. Techniques Gastrointest Endosc 2017; 19: $125-136$

[14] Hunt GC, Coyle WJ, Pais SA et al. Core curriculum for EMR and ablative techniques. Gastrointest Endosc 2012; 76: 725-729

[15] Bhurwal A, Bartel M], Heckman MG et al. Endoscopic mucosal resection: Learning curve for large nonpolypoid colorectal neoplasia. Gastrointest Endosc 2016; 84: 959-968 e957

[16] Draganov PV, Chang M, Roman RM et al. Role of observation of live cases done by Japanese experts in the acquisition of ESD skills by a western endoscopist. World J Gastroenterol 2014; 16: 4675-4680

[17] Soetikno R, Kaltenbach T. Dynamic submucosal injection. Gastrointest Endosc Clin N Am 2010; 20: 497-502

[18] Moss A, Williams S], Hourigan LF et al. Long term adenoma recurrence following wide-field endoscopic mucosa resection for advanced colonic mucosal neoplasia is infrequent: results and risk factors in 1000 cases from the Australian Colonic EMR study. Gut 2015; 1: 57-65

[19] Conio M, Repici A, Demarquay JF et al. EMR of large sessile colorectal polyps. Gastrointest Endosc 2004; 60: 234-241
[20] Kaltenbach T, Friedland S, Maheshwari A et al. Short- and long-term outcomes of standardized EMR of nonpolypoid (flat and depressed) colorectal lesions $\geq 1$. Gastrointest Endosc 2007; 65: 857-865

[21] Arebi N, Swain D, Suzuki N et al. Endoscopic mucosal resection of 161 cases of large sessile or flat colorectal polyps. Scand J Gastroenterol 2007; 42: 859-866

[22] Buchner AM, Guarner-Argente C, Ginsberg GG. Outcomes of EMR of defiant colorectal lesions directed to an endoscopy referral center. Gastrointest Endosc 2012; 76: 255-263

[23] Rex KD, Vemulapalli KC, Rex DK. Recurrence rates after EMR of large sessile serrated polyps. Gastrointest Endosc 2015; 82: 538-541

[24] Tsuji Y, Ohata K, Sekiguchi M et al. An effective training system for endoscopic submucosal dissection of gastric neoplasm. Endoscopy 2011; 12: 1033-1038

[25] Wani S, Keswani R, Hall M et al. A prospective multicenter study evaluating learning curves and competence in endoscopic ultrasound and endoscopic retrograde cholangiopancreatography among advanced endoscopy trainees: The rapid assessment of trainee endoscopy skills study. Clin Gastroenterol Hepatol 2017; 15: 1758-1767 e1711

[26] Rex DK, Hassan C, Dewitt JM. Colorectal endoscopic submucosal dissection in the United States: Why do we hear so much about it and do so little of it? Gastrointest Endosc 2017; 85: 554-558

[27] Fuccio L, Repici A, Hassan C et al. Why attempt en bloc resection of non-pedunculated colorectal adenomas? A systematic review of the prevalence of superficial submucosal invasive cancer after endoscopic submucosal dissection Gut 2018; 67: 1464-1474

[28] Hotta K, Oyama T, Shinohara T et al. Learning curve for endoscopic submucosal dissection of large colorectal tumors. Digest Endosc 2010; 22: 302-306 